\title{
Insightful Knowledge of Double Onset Constituency via the Standard and a Modified Optimality Theory
}

\author{
Sen-ling Lin \\ Kainan University, One Kainan Road, Luchu Shiang, Taoyuan 33857, Taiwan \\ Tel: 886-2-2891-1622Ｅ-mail: senling@ so-net.net.tw
}

Received: October 7, 2011

Accepted: December 7, $2011 \quad$ Published: February 1, 2012

doi:10.5539/ijel.v2n1p3

URL: http://dx.doi.org/10.5539/ijel.v2n1p3

\begin{abstract}
The current study reveals that the constraint-based standard optimality theory can better predict the co-occurrence of double onsets, whereas a corpus-data based optimality theory, which replaces a constraint tableau with a corpus-data table, can concentrate on the limited well-formed candidates, accounting more straightforwardly for interactions of the adjacent segments. In phonological processes, linear generative phonology is more clean-cut to explain the phonetic feature that influences adjacent segments. Optimality theory can have a pragmatic mode developed for the general public. As such, a new framework can make easier predictions and gain more insightful knowledge of double onset constituency, and does not have to resort to much terminology and sheer candidates generated, based on constraints for optimal outputs.
\end{abstract}

Keywords: Syllable onsets, Optimality theory, Generative phonology, Corpus data, Devoicing assimilation

\section{Introduction}

English is one of the languages whose syllables may contain multi-consonant onsets and codas on the two sides of vowel nuclei. Constituency in syllable onsets on the left margin is more salient than syllable codas on the right. Both the double marginal constituents are strictly arranged in sequence and are too intricate to be featured simply in a binary value system. Furthermore, Harrington and Cox (2009) point out that the syllable onset is a component where lie the most extreme phonotactic constraints, including combinatory, distributional and sonorous constraints, all of which govern the occurrences of sound sequences.

In phonological analysis, modern phonology has constantly been relying on rule-based generative phonology to gain insights into its internal constituency of syllable onsets. Its core principles are concerned with an underlying form to be developed into the surface form through ordered phonological rules. Nowadays, linguists have proposed an innovative framework for procedural analysis, known as optimality theory. However, this framework has also been reported to be a relatively sophisticated operating system with respect to a constraint tableau.

\section{Literature Review}

There has been much research on phonology. One of the prominent studies is optimality theory, originally proposed by Prince and Smolensky (1993), and McCarthy and Prince (1993). Its basic premises are noticeably different from other theories of phonology, as remarked by McCarthy (2007), who explains how to do analysis and research by dint of this non-rule framework.

This innovative analytical linguistic mode has been confirmed by many an eminent linguist as a well-established research paradigm. Kager (1999) illustrates that as developed from generative phonology, optimality theory is a mode of linguistic competence without going into the specifics of linguistic performance. Dekkers, et al. (2000) and Lombardi (2001) describe that this theory has revolutionized phonological theory and its insights are now being applied to other aspects of language. Féry (2007) asserts that this new framework replaces rules and transformations with a system of interactions and constraints.

Blutner (2004) asserts that this constraint-based linguistic framework is not restricted to phonology. Its applicability has been extended to morphology, syntax, semantics, pragmatics, historical linguistics and those related to language. Truckenblodt (1999) maintains that many issues concerning the prosodic constituents of syllables have been reconsidered in the light of optimality theory, which can provide insights into syllables. 
Nonetheless, some researchers have found evidence less consistent with the positive effect on specific formal analyses. Idsardi (2006) argues that optimality theory is an impossible model of articulation and perception and it would take an infinite long time to process the violable constraints. de Lacy (2007) points out that optimality theory is not a unified theory; there are a wide variety of approaches even within optimality theory. Gordon (2007) shows two complementary approaches: the formalist and functionalist, illustrating some areas in which phonetic factors can lead to an analysis in optimality theory and other functional factors.

Smolensky, Legendre and Tesar (2006) summarize key results that efficient generation is possible for any given optimality theory grammar but not for all, suggesting that there is an alternative representation of optimality theory grammars that allows for efficient computation of optimal surface forms and provides deeper insights into the sources of complexity of optimality theory. Gries (2007) verifies that corpus linguistics, referring to the main theoretical framework, can better explain and embed the analyses of a psychologically informed (cognitively-inspired) usage-oriented linguistics.

Blevins (2008) suggests that there are advantages of segmental and feature-based phonotactic constraints on consonant sequencing. Dobrić (2009) asserts that usage-based linguistics remains as the one of the best sources for language research and that the empirical nature of corpus-based linguistics allows for all of the research to have a solid base of concrete and statistical evidence for any manner of language analysis.

Aimed at searching for a simple and workable framework to gain insights of constituency of double onsets, the current study is to explore and compare the standard optimality theory with a modified framework with corpus data and linear generative phonology to determine whether the modified framework can provide an easier guide to phonological analysis and phonological description of how consonant segments combine and cluster together as double onsets of syllables.

\section{Assumption of the Study}

The study hypothesizes that double onsets of syllables are more sophisticated than single and triple onsets in constituency among the phonemic clusters that serve as syllable onsets, that there are cues together with principles that regulate two consecutive phonemes to form double onset clusters of syllables, that any principles of linguistics can be researched from the perspective of usage, and that among the phonological frameworks, the standard optimality theory, if modified as a usage-based linguistics by decreasing in technical terminology and a huge number of constraints in a constraint tableau, can provide a simpler, more illustrative account of how underlying forms develop into surface realizations with respect to double onsets of syllables.

\section{Method of the Study}

The current study attempts to get empirical insights of double onsets of syllables by two modes: the standard and a modified optimality theory. A concise introduction to optimality theory is rendered to optimality theory, which is reported to have its insights applied to many other central aspects of language. The other adopts modified processes that involve a replacement for a sophisticated constraint tableau with a table of well-prepared corpus data.

Analysis is made on both modes based on phonetic features and focusing on the manner of articulation of segments that may co-occur to form double onsets. A comparison is made between the two modes to determine which one is simpler and more efficacious in terms of the insightful knowledge of constituents of double onsets.

\section{Basic Architecture of Optimality Theory}

Optimality theory is one of the main frameworks of linguistic analysis developed in the decades. It was originally proposed by Alan Prince and Paul Smolensky and later expanded by John J. McCarthy and Alan Prince in 1993. Its premise is a set of universal constraints that prevent some segments from being violated candidates. This innovative approach maps input (underlying) forms to output (surface) forms, with different rankings of violable constraints and little phonological rule ordering and makes essential revisions of the fundamental notions of generative phonology as a dominant framework with an input-output based mode of general linguistics (Kager: 1999 and McCarthy: 2007). The one incurs the least serious violations of a set of constraints is chosen from the many possible forms as an optimal form (Prince and Smolensky: 2004).

Optimality theory is comprised of three fundamental components. Given an input, a generator, labeled GEN, produces a list of theoretically possible candidates, which are ranked, based on preference scale of the constraints, labeled CON, which provides the criteria, violable constraints, used to decide between candidates. Evaluation, labeled EVAL, chooses the optimal candidate, based on the constraints. In the final analysis, with disposal of candidates that violate crucial constraints, all that is left is the optimal candidate or the most harmonic surface output, which is strictly ordered candidates incurring no violations or the lowest-ranked 
violation on the constraint hierarchy.

In short, optimality theory proposes that an input generates all the possible candidates which are ranked. Violable constraints evaluate the ranked candidates and remove all the ill-forms. The most harmonic form is selected as the optimal output.

This new constraint-based framework can be recapped in a diagram designed by Dekkers, van der Leeuw, and van de Weijer (2000), showing a processing step-by-step solution to the understanding of operations in optimality theory.

\subsection{Sonority Hierarchy}

$$
\text { Input } \rightarrow \text { GEN } \rightarrow \text { Candidate set } \rightarrow \text { EVAL } \rightarrow \text { Optimal candidate }
$$

A sonority hierarchy is a ranking of speech sounds by amplitude: proportion to the ratio of energy produced in articulation. The nucleus is a sonority peak that is preceded and/or followed by a sequence of segments with increasing or decreasing sonority values (Spencer: 1996). It is one of the major constraints that determine permissibility of double onsets as optimal outputs.

The sonority hierarchy ranks speech sounds in sequence and divides them into groups, with reference to the sonority hierarchies designed by Hogg and McCully (1989), and according to the manner of articulation and the voicing of speech sounds. The sonority hierarchy table is designed in table 1 simply for English consonants, as obstruents and sonorants, ranking with a sonority value, while vowels are intentionally excluded, measured by the acoustic intensity of speech sounds, related to comparable pitches, degrees of length and stress (Ladefoged: 1993).

Nevertheless, not all speech sounds can cluster or co-occur with another speech sound to form double onset clusters. The segments that are parenthesized refrain from partial or full occurrences as double onsets. They are never preceded or followed by another consonant in double onsets; it is invariably absent from being in double onsets, as in the fricatives, $*(\check{\partial}),{ }^{*}(\mathrm{z})$ and $*(\breve{\mathrm{z}})$, the affricates * $(\breve{\mathrm{c}})$ and $*(\breve{\mathrm{J}})$, the nasal $*(\mathrm{y})-$, and the glide */(M)/-.

\subsection{Evaluation of Constraints on Double Onsets}

In optimality theory, evaluation of constraints is focused on a set of constraints in the constraint tableau. Candidates which violate combinatory constraints, phonotactic constraints, or the sonority sequencing practice are eliminated as ill-formed. Sound segments or candidates that violate constraints are marked with an asterisk '*'.

Consonant sequences cannot cluster as double onsets if violable to combinatory constraints, in addition to gaps:

- An accidental gap is a two-consonant sequence which is a possible but non-occurring form, as in $* / \mathrm{t} 1 /-, * / \mathrm{d} 1 /-$, $* / \theta 1 /, * / p w /-$, */bw/-, while in other cases, the obstruents may co-occur with $/ 1 /$ and $/ \mathrm{w} /$, as in $/ \mathrm{p} 1 /-, / \mathrm{bl} /-/ \mathrm{s} 1 /-$, $/ \mathrm{tw} /-/ \mathrm{dw} /-$.

- A systematic gap is what is impossible and absent from double onsets.

-The voiced retroflex */(r)/ and the glides */(w), (y)/- never serve as the initial double onsets.

-The voiced stops */(b), (d), (g)/ and the voiceless $* / \mathrm{h} /$ never occur as the second double onset.

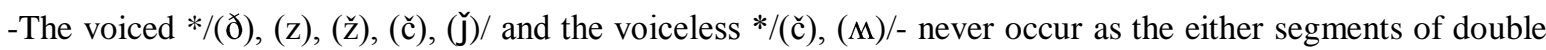
onsets. However, the voiceless glide $/ \mathrm{M} /$ in parentheses, the voiceless counterpart of $/ \mathrm{w} /$, never occurs in non-rhotic British English. It makes the total number of consonants to be twenty-five, as in $/ \mathrm{Ma}^{\mathrm{y}} /$ for $w h y$, in a single onset in rhotic General American, Irish and Scottish English.

- The sonority sequencing principle is another crucial constraint, as held by Harris (1994) and Kager (2004). Syllable onsets are arranged with a lower sonorous phoneme followed by a higher sonorous one in a double syllable onset: increase in sonority from left to right. Napoli (1996) further points out that generally it requires that segments within a double onset be separated by at least a certain distance apart on the sonority hierarchy.

\section{Observation of Constituency of Double Onsets}

The observations of constituency of double onsets are made on the standard optimality theory with the constraint tableau as well as on a modified optimality theory with a corpus data table. Attention is on the constraints, primarily based on the manner of articulation of obstruents and sonorants. A comparison is also made between the two modes to make out why one framework may be simpler and more effective than the other, in terms of getting the insightful knowledge of the constituency of double onsets for general readers. 


\subsection{Observation of a Constraint Tableau}

All the consonants are grouped into two main types in table 2: obstruents, including a stop (stp), a fricative (fri) and an affricate (aff), and sonorants, including a liquid (liq), nasal (nas) and glide (gli). Each cell in the tableau matrix indicates the result of the evaluation of the possible candidates in the leftmost column with respect to the combinatory constraints in the topmost row.

An asterisk $(*)$ is marked for a combinatory sequence that commits a constraint violation. An exclamation mark (!) on the right side of an asterisk is a candidate that incurs a crucial violation and refrains from being an optimal double onset; it is thus eliminated. An arrow $(\Rightarrow)$ marks the most harmonic output: an optimal candidate.

The voiceless obstruents can serve as the initial double onsets. For example, /p1/ can precede another consonant $/ \mathrm{O}_{2} /$ to form a double onset, labeled $/ \mathrm{p}_{1} /+/ \mathrm{O}_{2} /$. All possible candidates generated from the input are evaluated by two basic combinatory constraints together with the sonority.

In dealing with double onsets, faithfulness constraints need to be considered prior to markedness constraints together with the sonority sequencing principle, in that the stop /p/, the lowest sonorous segment, is followed by a sonorant: a higher sonorous segment.

\section{- Faithfulness Constraints}

- No reduplication of a consonant is allowed in English phonology.

- No obstruents can occur as $/ \mathrm{O}_{2} /$ in onset clusters if preceded by other than $/ \mathrm{s} /$.

\section{- Markedness Constraints}

- Only the liquids $/ l_{2}, \mathrm{r}_{2} /$ can occur after $/ \mathrm{p}_{1} /$, as in $/ \mathrm{p}_{1}+1, \mathrm{r}_{2} /$.

- Only the glide $/ \mathrm{y}_{2} /$ can cluster with $/ \mathrm{p}_{1} /$, as in $/ \mathrm{p}_{1}+\mathrm{y}_{2} /$.

- The Sonority Sequencing Principle: $/ O_{1} /$ (lower sonorous) $+/ O_{2} /$ (higher sonorous)

The optimal outputs of double onsets are the three uppermost candidates: $/ \mathrm{pl} /, / \mathrm{pr} /$ and $/ \mathrm{py} /$. The three sets of $/ \mathrm{p} /$ double onset clusters survive the evaluation of violable constraints that regulate that the stop $/ \mathrm{p} / \mathrm{can}$ precede only sonorants: the liquids $/ 1, \mathrm{r} /$ and the glide $/ \mathrm{y} /$. The three sequences have the fewest violations to phonotactic constraints; each of them violates only one constraint. These three well-formed candidates with SV's 6 and 7 are arranged in the upper preference scale of the constraint hierarchy, except for /s/ (SV. 2) (sonority value 2) to be followed by /p, t, k/ (SV. 1) (sonority value 1).

The other listed candidates in the constraint tableau are ranked, according to their phonetic features. Those in cells in columns 4-24 are ill-formed candidates. The nasals $/ \mathrm{m}, \mathrm{n} /$ never serve as the initial double onset $\left(O_{1}\right)$. The glottal fricative /h/ is never preceded by any segment $\left(O_{1}\right)$. The systematic gaps $* / \delta, z, \check{z}, \check{c}, \breve{j} /$ are never present either as a segment of double onsets $\left(O^{2}\right)$.

Candidates 4-20 are restrained from being double onsets, in that the second double onsets are obstruents: Only sonorants can serve as the second double onsets $\left(\mathrm{O}_{2}\right)$. Candidate 4 violates the constraint that no reduplication of a consonant segment. Candidates 5-9*(p + stp) breach the constraint that no oral stop can be the second double onsets $\left(\mathrm{O}_{2}\right)$ and the sonority scale values of the two segments are not separated by at least one sonority rank. Candidates $10-18 *\left(\mathrm{p}+\right.$ fri) are against the constraint that no fricative can be the second double onsets $\left(\mathrm{O}_{2}\right)$. Candidates $19-20 *(\mathrm{p}+$ aff $)$ never occur as double onsets $\left(O^{2}\right)$, in that no affricate occurs in a multiple onset, including a double $\left(O^{2}\right)$ and a triple onset $\left(O^{3}\right)$. Candidates $21-23 *(\mathrm{p}+$ nas $)$ infringe faithfulness constraints; nasals can be preceded only by /s/ in double onsets $\left(O^{2}\right)$.

Candidate $24, * / \mathrm{pw} /$ is eliminated as an ill-formed candidate; /p/ [+bilabial] $\left(O_{1}\right)$ does not co-occur with /w/ [+labiovelar] $\left(\mathrm{O}_{2}\right)$, in that the two segments share the same labial feature in the place of articulation. No two consecutive phonemes are allowed to be in the same point of articulation or too close to each other to hinder the ease of articulation (Locke: 1972).

Furthermore, what is concerned with in this study is phonology rather than typology. The five two-graph onsets $<\mathrm{pt}>,<\mathrm{pf}>,<\mathrm{ps}>,<\mathrm{ph}>$, and $<\mathrm{pn}>$ invariably represent phonologically as single onsets $\left(O^{1}\right)$, instead of double onsets $\left(O^{2}\right)$, and occur only in some very limited borrowings in orthography. The double-graph <ph>, for example, constantly stands for the voiceless labiodental fricative /f/ in all word positions, except that it can be phonetically realized as its voiced counterpart $/ \mathrm{v} /$, as in $/ \mathrm{nc}^{\mathrm{v} y u}{ }^{\mathrm{w}} /$ for nephew in British English. The other graphemic onsets, such as $\langle\mathrm{pt}>$, $<\mathrm{ps}>$, and $<\mathrm{pn}>$, stand for distinctive alveolar phonemes $/ \mathrm{t} /, / \mathrm{s} / \mathrm{and} / \mathrm{n} /$ with the initial /p/ elided, as in /tómigən/ for ptarmigan, /fénin/ for pfennig, /sa $\mathrm{s}^{\mathrm{y}} \mathrm{k} /$ for psyche, and $/ \mathrm{n}(\mathrm{y}) \mathrm{u}^{\mathrm{w}}$ mǽtik/ for pneumatic, respectively. 


\subsection{Observation of Corpus Data Tables}

A modified optimality theory employs a corpus data table, which replaces a constraint tableau. In the corpus data cited as corpus data in table 3 for double onsets, the few cells with a plus sign "+" are well-formed candidates, which are optimal outputs, while those with the parenthesized plus signs " $(+)$ " do not frequently occur. The cells in the corpus data table marked with a minus sign "-" are deemed to be ill-formed candidates; they violate combinatory constraints and do not occur as double onsets even though some of them may conform to English phonological structures.

\subsubsection{Constructing a Corpus Data Table}

The corpus data table 3 involves exhaustive well-formed double onsets in English phonology. The possible candidates are two-consonant sequences, which are made up of the initial double onsets $\left(O_{1}\right)$ in the column and the second double onsets $\left(\mathrm{O}_{2}\right)$ in the row, formulated as $\mathrm{O}_{1}+\mathrm{O}_{2}$.

Not all the well-formed outputs of double onsets are productive of forming words; some are permissible but seldom used as double onsets. The double onset $/\left(\mathrm{v}_{1} \mathrm{r}_{2}\right) /$ can hardly serve as the norm; it occurs in the only word vroom as an exclamation imitative of a car engine revving up; it can be realized as the monosyllabic $/ \mathrm{vru}\left({ }^{\mathrm{w}}\right) \mathrm{m} / \mathrm{or}$ the disyllabic word [vərú( $\left({ }^{\mathrm{w}}\right) \mathrm{m}$ ] for varoom.

Besides, a two-velar onset /gw/ cluster, consisting of $/ \mathrm{g}_{1} /$ [+velar] and $/ \mathrm{w}_{2} /$ [labiovelar], occur only in a few loanwords, as in /gwóva/ for guava, the fruit of a tropical American shrub, /gwam/ for Guam, an unincorporated territory of the United States in the Pacific, and /gyúw dòn/ for gyudon, a Japanese beef bowl, in that $/ \mathrm{u}^{\mathrm{w}} /$ is close to $/ \mathrm{w} /$ in value as the onset in $/ \mathrm{g}_{1} \mathrm{yu}^{\mathrm{w}}{ }_{2} /$ cluster. These very few borrowings are listed as lexical entries only in unabridged dictionaries.

\subsubsection{Optimal Double Onsets}

The optimal double onsets are well-formed candidates comprised of three distinctive consonants: obstruents $\left(O_{1}\right)$ plus obstruents $\left(O_{2}\right)$, obstruents $\left(O_{1}\right)$ plus sonorants $\left(O_{2}\right)$ and sonorants $\left(O_{1}\right)$ plus sonorants $\left(O_{2}\right)$, and incur no violations or the lowest-ranked violation on the voicing, place and manner of articulation, and the sonority sequencing principle. Only in some limited cases, is the initial $/ \mathrm{s} /\left(O_{1}\right)$ allowed to precede either an obstruent or a sonorant $\left(\mathrm{O}_{2}\right)$ as double onsets

Below are optimal double onsets, while the less frequently occurring double onsets are parenthesized; they are listed as lexical entries only in unabridged dictionaries. Those systematic gaps are excluded and do not appear below.

\section{- Obstruents-Obstruents/Sonorant Clusters}

- /s/ plus obstruents: /sp, st, sk/-, e.g. spit, stem, sky and /sf/-, e.g. sphere.

- /s/ plus sonorants: /sl, sm, sn, sy, sw/, e.g. slab, smell, snail, suit, sweat.

Contrary to the regular upward sonority sequencing principle for double onset clusters, the $/ \mathrm{s}_{1} O_{2} /$ - is arranged in a downward sonority slope but are allowed to be optimal surface outputs: the fricative $/ \mathrm{s}_{1} /$ (SV.2) followed by the stops $/ \mathrm{p}_{2}, \mathrm{t}_{2}, \mathrm{k}_{2} /$ (SV.1) can compose double onsets: $/ \mathrm{s}_{1} \mathrm{p}_{2} /, / \mathrm{s}_{1} \mathrm{t}_{2} /$ and $/ \mathrm{s}_{1} \mathrm{k}_{2} /$, as in $/$ spit/ for spit, /star/ for star and /skin/ for skin, respectively.

In rare cases, the two voiceless $/ \mathrm{s}_{1} \mathrm{f}_{2} /$, featured as fricatives with the same manner of articulation and the same sonority values (SV.2 + SV.2), can form optimal double onsets, as in the loanword /sfir/ for sphere cognate with Latin 'sphaera' and Greek 'sphaira' and the foreign words /sfinks/ for sphinx in Greek mythology, and the Italian $/ \mathrm{sfu}^{\mathrm{w}} \mathrm{máto}^{\mathrm{w}} /$ for sfumato, meaning evaporation.

The double onset clusters $/ \mathrm{s}_{1} \mathrm{l}_{2} /$ and $/ \breve{\mathrm{s}}_{1} \mathrm{r}_{2} /$ are generally in complementary distribution. The alveolar fricative $/ \mathrm{s}_{1} /$ occurs before the lateral $/ l_{2} /$, whereas the palatal fricative $/ \check{s}_{1} /$ occurs before the retroflex $/ \mathrm{r}_{2} /$. Only in a very few words of Yiddish origin, is $/ \breve{s}_{1} /$ allowed to precede $/ l_{2} /$, as in $/{ }_{s} l \alpha k /$ for schlock, meaning evil and nuisance.

- Obstruents-Sonorant Clusters

a. Stops plus (1) liquids: /pl, kl, pr, tr, kr, bl, gl, br, dr, gr/-;

(2) glides:/ py, ty, ky, tw, kw, by, dy, (gy), dw, (gw)/-.

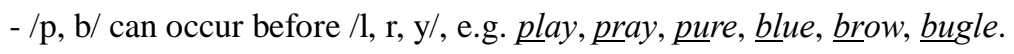

- /t, d/ can occur before /r, (y), w/, e.g. try

- /k, g/ can occur before /l, r, w, y/, e.g. club, crow, quit, cute, glue, grip, (guava). 
b. Fricatives plus liquids: /fl, fr, $\theta \mathrm{r}, \mathrm{sl}, \mathrm{s} r /-$ :

- /f, v/ can occur before /l, r, y/, e.g. fly, fry, feww, view, (room).

$-/ \theta$, š/ can occur before /r/, e.g. throw, shrink.

-/s/ can occur before /1/, e.g. slip.

c. A fricative plus a glide: /hy/-:

- /h/ can occur before /y/, e.g. huge.

- Sonorants-Sonorant Clusters

a. Nasals plus a glide: /my, ny/-, e.g. muse, new.

b. Lateral plus a glide: /ly/-, e.g. $\underline{\text { ieu }}$.

Dialects lead to regional variations in pronunciation, vocabulary, etc. Shuy (1980) expresses that the palatal glide /y/ after alveolars is susceptible to dialect variations. Most speakers of American English speak with a palatal glide $/ \mathrm{y} /$ before the diphthong $/ \mathrm{u}^{\mathrm{w}} /$ as optional in double onset clusters when preceded by the alveolars $/ \mathrm{t}, \mathrm{d}, \mathrm{s}, \mathrm{z}, \mathrm{l}$, $\mathrm{n} /-$.

\subsubsection{Violated Candidates}

Two-consonant sequences for double onsets are ill-formed when violable to the combinatory constraints, including phonetic features in voicing, place and manner of articulation, and/or the upward sonority sequencing principle.

One of the highest violable constraint tableaux is no reduplication of any consonant in English phonological structure. Some segments are constrained from clustering as double onsets. Sonorants are prohibited from being the initial double onsets $\left(O_{1}\right)$ except that the liquid $/ 1 /$ and the nasals $/ \mathrm{m}, \mathrm{n} /$ can be followed by the glide $/ \mathrm{y} /\left(O_{2}\right)$. All obstruents are not allowed to be second double onsets $\left(O_{2}\right)$ except that the fricative $/ \mathrm{s} /\left(O_{1}\right)$ precedes voiceless stops $\left(\mathrm{O}_{2}\right)$.

(a) Constraints on Place of Articulation

Two distinctive phonemes are constrained from being double onsets if homorganic; two-phoneme sequences are too close to be articulated distinctly in articulatory position.

- No two labials can cluster, e.g. */pw, bw, fw, vw, mw, pf, bf/-.

- No two alveolars can cluster except for /sl, sn/, e.g.*/tl, dl, nl, tn, dn/-.

- No two palatals except for/šr/ can cluster, e.g. */šy, žy, čy, J̌y/-.

- No two velars can cluster except for /(gw)/, e.g. */ng yw, gy, wy/-.

The syllable onsets /tr, $\mathrm{dr} /$ are permissible, thus optimal; the second segment $/ \mathrm{r} /$ is retroflex, featured as palatal or more precisely alveo-palatal and articulated at a point a little more retracted backward than the alveolar position.

(b) Constraints on Manner of Articulation

More constraints on the manner of articulation can be observed than those on the place of articulation in double onsets. Systematic gaps are those that never co-occur with other segments, as in obstruents, including the affricates */č $\breve{\jmath} /-$ and some voiced fricatives $* / \check{\partial}, \mathrm{z}, \breve{z} /-$, and sonorants, including the glides */y, w/-. Others are accidental gaps featured in the same manner of articulation. The two sets of ill-formed candidates are constrained from being in double onsets as follows.

- No two obstruents can cluster except for/sp, st, sk; sf/-.

- No voiced obstruents can occur as the second double onset $\left(O_{2}\right)$.

- No fricatives except for /f, s/- $\left(O_{1}\right)$ can cluster with the lateral /1/ $\left(O_{2}\right)$-.

- No fricatives except for $/ \theta, \mathrm{s} /-\left(O_{1}\right)$ can occur before the glide /w/- $\left(O_{2}\right)$.

- No fricatives */ð, z, ž/ can be either segment of double onsets.

- No affricates */č, j/ can be either segment of a double onset.

- No two sonorants can cluster except for /ly, my, ny/.

- No liquid retroflex $* / r /$ - can occur as the initial double onset $\left(O_{1}\right)$.

- No nasal $* / \mathrm{y} /$ can serve as either segment of a double onset. 
- No nasals *-/m, n/ $\left(O_{2}\right)$ can be preceded by any segments except for the fricative /s/- $\left(O_{1}\right)$.

- No glides */y, w/- can occur as the initial double onset $\left(O_{1}\right)$.

(c) Harmony in the Internal Sonority Ranking

Double onsets are usually dominated by the upward sonority sequencing principle. Double onsets consist of obstruents (the lower sonority level) $\left(O_{1}\right)$ and sonorants (the greater sonority level) $\left(O_{2}\right)$. The sonorant, when preceded by a voiceless obstruent, is partially devoiced in actual speech if the two adjacent consonants have very diverse sonority rankings.

Devoicing assimilation is a phonological process by which the voiced phonetic feature is deleted from the feature matrix. The two segments of onset clusters are naturally harmonized by lowering the sonority value of the second segment. As a result, the two immediately adjacent phonemes with opposite voices turn out murky and closer to each other in sonority rankings.

It is a common practice in English phonology that sonorants (SV's 4-6), including the nasals /m, n/ (SV.4), the liquids /l, r/ (SV.5), and the glides /y, w/ (SV.6), are partially devoiced when preceded by the voiceless stops /p, t, k/ (SV.1) (Catford: 1988) and the voiceless fricatives /O, s, š h/ (SV.2) (Spencer: 1996). As such, two segments in sequence with diverse voice are made easier to articulate (Kreidler: 1995 and McCarthy: 2011).

\section{Devoicing Assimilation in Different Modes}

The attention of devoicing assimilation of two modes is on single phonological phenomena by means of optimality theory and linear generative phonology. English is an anticipatory language: The second double onset [+voice] is subject to devoicing when preceded by the initial onset [-voice] to an extent of the opening of the glottis.

Both constraint-based optimality theory and rule-based generative phonology can account for the devoicing assimilation of sonorants after voiceless obstruents. The descriptions of the two modes in devoicing assimilation are compared, taking into account of simplicity and economy in the devoicing of sonorants after voiceless obstruents.

\subsection{Optimality Theory: devoicing assimilation}

The sonorants $\left(\mathrm{O}_{2}\right)$ [+voice], including the liquids $/ \mathrm{l}, \mathrm{r} /$, the nasals $/ \mathrm{m}, \mathrm{n} /$ and the glides $/ \mathrm{w}, \mathrm{y} /$, are partially devoiced when preceded by the obstruents $\left(O_{1}\right)$ [-voice], including the stops $/ \mathrm{p}, \mathrm{t}, \mathrm{k} /$ and the fricatives $/ \theta, \mathrm{s}, \breve{\mathrm{s}}, \mathrm{h} /$.

There would be another seven tableaux to account for devoicing assimilation. However, observation is made on the double onset: the fricative /s/ plus the sonorants /l, m, n, w, y/; in that it can occur before consonants more than any consonants.

- Faithfulness Constraints:

- The fricative /s/ precedes the stops /p, t, k/ and the fricative /f/, and the sonorants /m, n; w, y/.

- The sonorants are devoiced after the voiceless obstruent $/ \mathrm{s} /$.

- Markedness Constraints

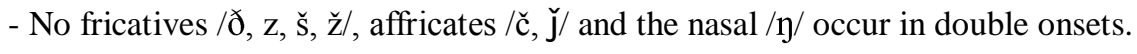

- No sonorants $\left(O_{2}\right)$ are devoiced except after the voiceless obstruent $\left(O_{1}\right)$.

- No retroflex $/ \mathrm{r} /\left(\mathrm{O}_{2}\right)$ occurs after the fricative $/ \mathrm{s} /\left(O_{1}\right)$.

- No voiced obstruents $\left(O_{2}\right)$ are preceded by any segments $\left(O_{1}\right)$.

Twenty-four, $/ \mathrm{N} /$ excluded, possible candidates are generated from an input by having $/ \mathrm{s}_{1} /$ combined with another segment as $/ O_{2} /$ for the tableau in the standard optimality theory. Candidates 1-9 are permissible, which consist of $/ \mathrm{s}_{1} /$ and $/ O_{2} /$ (SV's 2), including the obstruents /p, t, k; f/ (SV's 1-2) and the sonorants /l; m, n, y, w/ (SV's 4-5). The voiceless feature of the initial voiceless segment influences its following sonorant to be devoiced or become voiceless, whereas the voiceless obstruents remain unchanged in voice features.

However, the well-formed corpus data in table 4 illustrate that the second sonorant segments of all the double onsets are devoiced after the voiceless obstruent /s/ in actual speech. Candidates 1-4 [sl, sm, sn, sw] are the most harmonious outputs; [sw] is equivalent to $[\mathrm{sM}]$ in phonetic value, only with difference in symbols; candidate 5 [sy] can be the optimal output in British English, as in $\left[\mathrm{syu}^{\mathrm{w}}\right]$ for $\underline{\text { sue }}$, but $/ \mathrm{y} /$ is elided after an alveolar in American English. 
Candidates 6-9 can be optimal outputs in phonemic or phonetic representations; however, no devoicing assimilation may occur to any voiceless obstruents as second segments. Candidate $6 / \mathrm{sf} /$ consists of two voiceless fricatives ranking with the same sonority values. Candidates 7-9 are suppletive double-onset clusters: They are in reverse order in sonority sequencing sequences: VS2 +VS1.

All the other two-segment sequences are ill-formed candidates. Candidates 10-12, */sb, sd, sg/-, never occur as double onsets, in that $/ \mathrm{s} /$ is followed by obstruents, which must be voiceless, as double onsets. Candidates 13-19 are eliminated; no two-fricative sequences $* / s \theta$, ss, šs, sh, sv, sð, sz, š̌ / are allowed to form double onsets except for /sf/-. Candidates 21, 22 and 24 are two-segment sequences */sč, š, s引/ are systematic gaps: The affricates and the velar nasal never occur in double onsets. Candidate $23 * / \mathrm{sr} /$ is an accidental gap; the retroflex $/ \mathrm{r} /$ cannot be preceded by the alveolar fricative /s/ in a double onset.

\subsection{Generative Phonology: devoicing assimilation}

Not as with the standard optimality theory, generative phonology focuses more on phonetic features involving linear juxtaposition of segments and deals with interactions of adjacent phonemes in a phonological environment. The rules which generate double onsets can cover the phonological processes for voiceless obstruents followed by sonorants, including /1, r/ [+liquid], /m, n/ [+nasal], and /y, w/ [+glide]: The sonorants are partially devoiced When preceded by the stops / $\mathrm{p}, \mathrm{t}, \mathrm{k} /$ [-voice], the liquids $/ 1, \mathrm{r} /$ [+voice] are partially devoiced as [1, r] [-voice], as in [pliy d] for plead, [klik] for click, [pray ${ }_{0}^{\mathrm{y}} \mathrm{d}$ for pride, [triy] for tree, and [kraw $\left.{ }_{0}^{\mathrm{w}} \mathrm{d}\right]$ for $c \underline{r o w d}$, etc. and by the

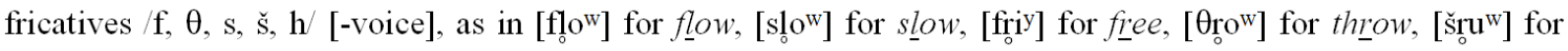
shrew, $\left[h_{g} \mathbf{u}^{\mathrm{w}}\right]$ for $h \underline{e} w$, etc.

Similarly, when preceded by the fricative / $\mathrm{s} /$ [-voice], the nasals $/ \mathrm{m}, \mathrm{n} /$ are partially devoiced as $\left[\mathrm{m}_{0} \mathrm{n}\right]$, as in

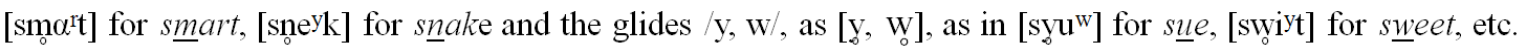

The observations above can be represented in the formulaic representations as below:

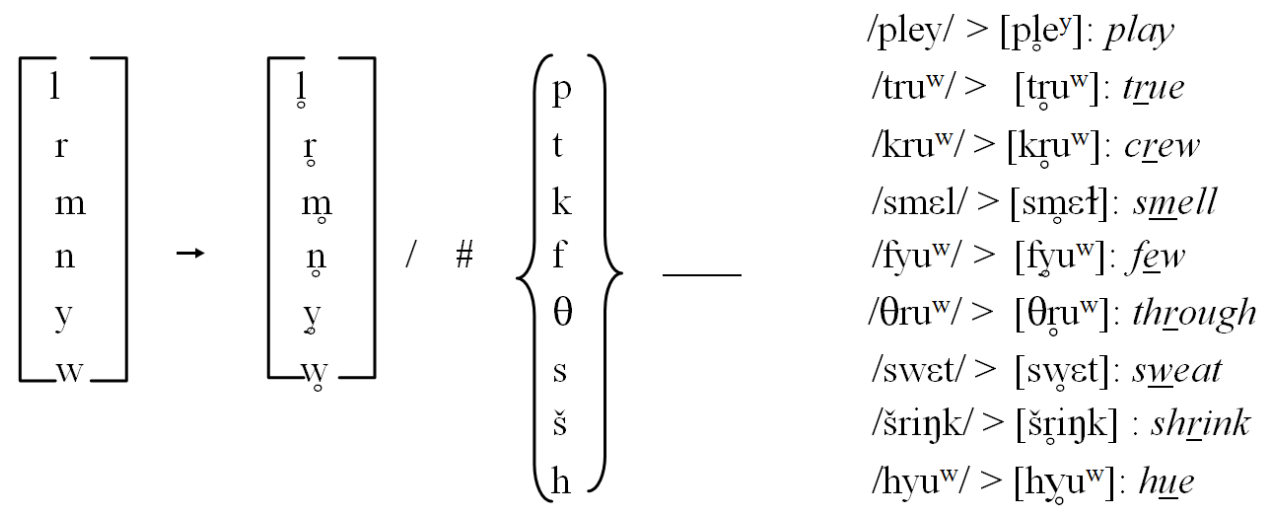

The formulaic representations above can be converted to feature representations; the description is focused on all but only those segments which would be affected in the segment inventory.

$$
[+ \text { son }] \rightarrow[-\mathrm{vd}] / \quad \#\left[\begin{array}{l}
+ \text { obs } \\
-\mathrm{vd}
\end{array}\right]
$$

The above rule is read: a sonorant is devoiced when preceded by a voiceless obstruent.

\section{Comparison Between the two Modes}

The comparison of the two modes reveals that the standard optimality theory needs to build over-abundant constraint tableaux for each of the seven voiceless obstruents followed by sonorants, while linear generative phonology provides a simpler and more clear-cut account of the devoicing assimilation of sonorants in one collapsed formulaic representation or prose description.

The modified optimality theory would be easier and more distinct for general readers to understand the phonological effects resulting in devoicing assimilation, providing more information about how phonological processes undergo phonological changes when the two immediately adjacent phonemes interact with each other. By comparison, the standard optimality theory maps from inputs to outputs with little explanatory description of the co-occurrences of devoicing assimilation. It requires much linguistic knowledge to generate, rank and evaluate the theoretically infinite candidates for well-formed candidates as scrutinized by Heinzy, Kobele, and Riggle (2009). 


\section{Discussion}

The standard optimality theory, as claimed by its proponents, is a new revolutionized linguistic framework and gives fresh perspectives with respect to phonology and many other aspects, including language and business management (Blutner and Zeevat, 2004). The current modified one can be employed as a clean-cut means in phonological analysis with basic knowledge about phonetic features.

Furthermore, practicing this new innovative framework involves a huge number of constraints and candidates in constraint tableaux with new terminology, while more time and effort will be needed to evaluate and eliminate ill-formed candidates, based on markedness constraints (linguistic performance) which should refer to faithfulness constraints (linguistic competence): These two main constraints are cornerstones of optimality-theoretic analysis. Faithfulness constraints regulate that the outputs resemble the input, and markedness constraints impose requirements on the well-formed output not to deviate from the faithfulness constraints (Kager: 2004).

Nonetheless, all the constraints in tableaux of optimality theory are innate; the innate ability is essential for language acquisition as asserted by Tesar and Smolensky (1998) and Williamson (2009). In applied English, non-native speakers, whose English proficiency is below intermediate levels or who are not equipped with basic knowledge of phonology, are very likely to experience much difficulty generating infinite candidates, to say nothing of ranking and evaluating a vast number of candidates for well-formed candidates.

The slightly modified optimality theory has a constraint tableau replaced with a feature-based mode which contains the well-prepared corpus data confined to a small number of well-formed candidates, thus providing phonological processes with straightforward account of interactions of the adjacent segments in devoicing assimilation.

Electronic devices in modern technology can facilitate processes in phonological analysis. As stated by MiniCorp Inform Page (2008), the computer software developers, the software of optimality theory is intended primarily as automatic analyses and learning, and it is helpful to solve the fundamental problem of optimal outputs and corpus statistics. Nonetheless, pencil and paper algorithm analysis can provide more insights into the constituency of double onsets. The statistics for the optimal outputs do not involve related phonetic features and phonological processes that account for interactions of the adjacent segments that lead to the surface realization outputs.

Like many other innovative phonological modes, the standard optimality theory has been introduced and continually improved. A novel mode will come along with original premise of optimality theory, pragmatically incorporate other theories of linguistics, and make its practice ancillary procedures to the standard optimality theory and more analytical to new issues. However, all these procedures crave linguistic competence. Jusczyk, Smolensky and Allocco (2002) referred to an avant-garde mode as the factorial typology with the aim of arriving at an economical and adequate description of lexical phonological representations. As a result, phonological analysis can be made more enjoyable and productive with respect to more insightful knowledge of internal constitutes of double onsets of syllables.

\section{Conclusion}

The current study indicates that the constraint-based standard optimality theory is a mode that can predict how two segments can cluster as double onset. The slightly modified mode of optimality theory with a feature-based corpus data table concentrates on the small number of well-formed candidates; therefore, it can provide more straightforward account of interactions of the adjacent segments and typological possibilities. However, this modified mode loses its prediction ability due to having to rely on the fully-prepared corpus data for further phonological analysis.

There is plenty of space that can improve and develop an effective mode with the premise of the standard optimality theory. An avant-garde one can include a pragmatic approach that is able to predict and account for the co-occurrences of sound segments in double onsets as well as may have easy access to in-depth knowledge of the clustering of double onsets but does not have to resort to much terminology and innateness to generate, rank and evaluate enormous theoretically possible candidates in a constraint tableau.

\section{References}

Archangeli, Diana B. \& Langendoen, D. Terence (Eds.). (1997). Optimality theory: An Overview. Oxford, England: Blackwell Publishers Ltd.

Blevins, Juliette. (2003). The independent nature of phonotactic constraints: An alternative to syllable-based 
approaches. The syllable in optimality theory. Caroline Féry Ruben van de Vijver (Eds.). 375-404.

Blutner, Reinhard \& Zeevat, Henk. (2004). Optimality Theory and Pragmatics: Palgrave Studies in Pragmatics, Languages and Cognition. Berlin, German: Palgrave Macmillan, Ltd. ISBN-10: 1403901295.

Burzio, L. (1995). The rise of optimality theory. GLOT, 1.6, August, 3-7.

Catford. J. C. (1988). A practical introduction to phonetics. Oxford England: Oxford University Press, 208-210.

Chomsky, Noam \& Halle, Morris. (1991). The sound pattern of English. New York: Harper and Row Publishers.

Clements, George Nick. (1985). The geometry of phonological features. Phonology Yearbook 2. New York: Harper \& Row, 223-252.

Dekkers, Joost Leeuw, van der Weijer, Frank \& van de Weijer, Jeroen. (2000). Optimality theory: phonology, syntax, and acquisition. Wotton-under-Edge, Gloucestershire, England: Clarendon Press, 2.

de Lacy, Paul. (2007). Themes in phonology. The Cambridge handbook of phonology. Paul de Lacy (Ed.). Cambridge: Cambridge University Press, 5-30.

Dobrić, Nikola. (2009). Corpus Linguistics as a basic form of language research. Language, Literature and Identity. Misic, Lopicic (Hrsg). Niš, Serbia: Faculty of Philosophy at the University of Niš, 359-363.

Féry, Caroline. (2007). The prosody of topicalization. On Information Structure, Meaning and Form. Schwabe, Kerstin and Susanne Winkler (Eds.), 69-86.

Féry, Caroline \& Ruben van de Vijver. (Eds.). (2004). The syllable in optimality theory. Cambridge, England: Cambridge University Press, 4-5.

Gimson, A.C. (1989). An introduction to the pronunciation of English. $\left(4^{\text {th }}\right.$ ed.). London, England: Edward Arnold Publishers, 241-248.

Gordon, Mathew. (2007). Functionalism in phonology. The Cambridge handbook of phonology. Paul de Lacy (Ed.). New Jersey: Rutgers University, New Jersey, 61-78.

Gries, Stefan Th. (2010). Useful statistics for corpus linguistics. A mosaic of corpus linguistics: selected approaches. Aquilino Sánchez \& Moisés Almela (Eds.). Frankfurt am Main: Peter Lang, 269-291.

Halle, Morris. (1995). Feature Geometry and Feature Spreading. Linguistic Inquiry, 26, 1-46.

Harrington, Jonathan \& Cox, Felicity. (2009). Phonetics and phonology: The syllable and phonotactic constraints. Sidney, Australia: Macquarie University.

Harris, John. (1994). English sound structure. Oxford, England: Blackwell Publishers Ltd., 50-56.

Hawkins, Peter. (1992). Introducing phonology. London, England: Routledge.

Heinz, Jeffrey, Kobele, Gregory M. \& Riggle, Jason. (2009). Evaluating the Complexity of Optimality Theory. Linguistic Inquiry, 40 (2) 277-288. http://dx.doi.org/10.1162/ling.2009.40.2.277

Hogg, Richard M. \& McCully, C.B. (1989). Metrical phonology: a coursebook. Cambridge, England: Cambridge University Press, 32-41.

Hymes, Dell Hathaway. (1971). Competence and performance in linguistic theory. Language acquisition: models and methods, 3-28.

Jones, Charles. (1989). A history of English phonology. Essex. England: Longman Group UK Limited.

Jusczyk, Peter W. Smolensky, Paul \& Allocco, Theresa. (2002). How English-learning infants respond to markness and faithfulness constraints. Language Acquisition, 10(1), 31-73. http://dx.doi.org/10.1207/S15327817LA1001_3

Kager, René. (1999/2004). Optimality theory. Cambridge University Press, xi-xiii, 3-13, 25-27, 83-84, 91-116.

Kreidler, Charles W. (1995). The pronunciation of English: a course book in phonology. Oxford, England: Blackwell Publishers Ltd., 117-121 and 262-271.

Ladefoged, Peter. (1993). A course in phonetics ( $3^{\text {rd }}$ ed.). Orlando, Florida: Harcourt Brace \& Company, 245-246.

Lambardi, Linda. (2001). Segmental phonology in optimality theory: constraints and representations. Cambridge, England: Cambridge University Press.

Locke, John L. (1972). Ease of articulation. Journal of Speech and Hearing Research, 15(1): 194-200. 
Longman Dictionary of Contemporary English ( $4^{\text {th }}$ ed.). (2003). Essex: England: Person Education Limited.

Mahlberg, Michaela. (2006). Lexical cohesion: Corpus linguistic theory and its application in English language teaching. International Journal of Corpus. Linguistics, 11(3): 363-383.

Merriam-Webster's Collegiate Dictionary (11 ${ }^{\text {th }}$ Ed.). (2009). Springfield, Massachusetts: Merriam-Webster, Incorporated.

McCarthy, John J. (2007). What is optimality theory? Language and Linguistics Compass 1. Amherst, Massachusetts: University of Massachusetts, 260-291.

(2011). Autosegmental spreading in optimality theory. Tones and Features. John Goldsmith, Elizabeth Hume and Leo Wetzels (Eds.). Berlin, Germany: Mouton de Gruyter, 1-3.

McQueen, James. (1988). Segmentation of continuous speech using phonotactics. Journal of memory and language, 39: 21-46. http://dx.doi.org/10.1006/jmla.1998.2568

MiniCorp Inform Page. (2008). Why phonological corpus analysis? What is MiniCorp. [Online] Available: ccunix.ccu.edu.tw/ Ingproc/MCInfo.htm (January 24, 2008)

Napoli, Donna Jo. (1996). Linguistics. New York: Oxford University Press, Inc., 70-102, 143.

Prince, Alan. (2007). The Pursuit of Theory. Cambridge handbook of phonology. Paul de Lacy (Ed.). Cambridge: Cambridge University Press.

Prince, Alan \& Smolensky, Paul. (1993/2002/2004). Optimality theory: Constraint interaction in generative grammar. Malden, Massachusetts: Blackwell Publishers Ltd., 215-217.

Roach, Peter. (1983). English phonetics and phonology: A practical course. Cambridge, England. Cambridge University Press.

Selkirk, O. Elisabeth. (1982). The syllable. In The structure of phonological representations (part II). I-I. van der Hulst \& N. Smith, (Eds.), 337-83.

(2000). The interaction of constraints on prosodic phrasing. Prosody: theory and experiment. Merle Horne

(Ed.). Dordrecht: Kluwer. Academic Publishing, 231-262.

Shuy, Roger W. (1980). Dialects: How they differ. Language: introductory readings (2nd ed.).

Spencer, Andrew. (1996). Phonology. Oxford, England: Blackwell Polishers Ltd.

Tesar, Bruce \& Smolensky, Paul. (1998). Learnability in optimality theory. Linguistic Inquiry, 29(2):229-268. http://dx.doi.org/10.1162/002438998553734

Truckenbrodt, Hubert. (1999). On the relation between syntactic phrases and phonological phrase. Linguistic Inquiry, 30: 210-235. http://dx.doi.org/10.1162/002438999554048

Williamson, Graham. (2009). Innate ability for language acquisition. Last updated on October 13, 2009, on Google. Wolfram, Walt \& Johnson, Robert. (1982). Phonological analysis: focus on American English. Upper Saddle River, New Jersey: Prentice-Hall, Inc.

Yallop, Colin \& Clark, John. (1990). An introduction to phonetics phonology. Oxford, England: Blackwell Ltd. Yavaş, Mehmet. (2006). Applied English phonology. Malden, Massachusetts: Blackwell Publishing.

Table 1 . Sonority Hierarchy Table

\begin{tabular}{|c|c|c|c|c|c|c|c|}
\hline & \multicolumn{2}{|c|}{ lowest sonority } & \multicolumn{4}{|c|}{ highest sonority } \\
\hline \multicolumn{2}{|c|}{ natural class } & \multicolumn{3}{|c|}{ obstruents } & \multicolumn{3}{|c|}{ sonorants } \\
\hline \multicolumn{2}{|c|}{ sonority values } & SV. 1 & (SV. 2) & SV. 3 & SV. 4 & SV. 5 & SV. 6 \\
\hline \multicolumn{2}{|c|}{ phonetic features } & stops & (affricates) & fricatives & nasals & liquids & glides \\
\hline \multirow[t]{2}{*}{ voicing } & [+voice] & $/ b, d, g /$ & $/(\breve{\mathrm{j}}) /$ & /v, (ð), (z), (̌z)/ & $/ \mathrm{m}, \mathrm{n},(\mathrm{y}) /$ & $/ 1, \mathrm{r} /$ & $/ \mathrm{y}, \mathrm{w} /$ \\
\hline & [-voice] & $/ \mathrm{p}, \mathrm{t}, \mathrm{k} /$ & $/(\check{\mathrm{c}}) /$ & $/ \mathrm{f}, \theta, \mathrm{s}, \check{\mathrm{s}}, \mathrm{h} /$ & & & $/(M) /$ \\
\hline
\end{tabular}

The hierarchy is scaled from left to right, ranging from the least sonorous (SV.1) to most sonorous (SV.6) by the acoustic intensity of speech sounds, related to comparable pitches, degrees of length and stress (Ladefoged: 1993). The voiced obstruents carry a value slightly higher than their voiceless counterparts, but voice features do not affect the current survey of double onsets. The liquids rank one notch higher than nasals in General American English. 
Table 2. Constraint Tableau of Double Onsets

\begin{tabular}{|c|c|c|c|c|c|c|c|}
\hline \multirow{3}{*}{\begin{tabular}{|c|}
$\mathrm{p}_{1}+\mathrm{O}_{2}$ \\
possible \\
candidates
\end{tabular}} & \multicolumn{3}{|c|}{$\mathrm{p}_{1}+$ obstruent $_{2}$} & \multicolumn{4}{|c|}{$\mathrm{p}_{1}+$ sonorant $_{2}$} \\
\hline & \multirow[t]{2}{*}{$\mathrm{p}_{1}+\mathrm{stp}_{2}$} & \multirow{2}{*}{$\mathrm{p}_{1}+\mathrm{fri}_{2}$} & \multirow[t]{2}{*}{$\mathrm{p}_{1}+\mathrm{aff}_{2}$} & \multirow[t]{2}{*}{$\mathrm{p}_{1}+\mathrm{nas}_{2}$} & \multirow[t]{2}{*}{$\mathrm{p}_{1}+\mathrm{liq}_{2}$} & \multicolumn{2}{|l|}{$\mathrm{p}_{1}+\mathrm{gli}_{2}$} \\
\hline & & & & & & $\mathrm{p}_{1}+\mathrm{w}_{2}$ & $\mathrm{p}_{1}+\mathrm{y}_{2}$ \\
\hline sonorant values & SV.1+SV.1 & SV.1+SV.2 & SV.1+SV.3 & SV.1+SV.4 & SV.1+SV.5 & \multicolumn{2}{|c|}{ SV.1+ SV.6 } \\
\hline$\Rightarrow 1 . \mathrm{pl}$ & $*$ & $*$ & $*$ & $*$ & & $*$ & $*$ \\
\hline$\Rightarrow 2 . \mathrm{pr}$ & $*$ & $*$ & $*$ & $*$ & & $*$ & $*$ \\
\hline$\Rightarrow 3 . \mathrm{py}$ & $*$ & $*$ & $*$ & $*$ & $*$ & $*$ & \\
\hline 4. $\mathrm{pp}$ & $* !$ & $*$ & $*$ & $*$ & $*$ & $*$ & $*$ \\
\hline 5. pt & $* !$ & $*$ & $*$ & $*$ & $*$ & $*$ & $*$ \\
\hline 6. $\mathrm{pk}$ & $* !$ & $*$ & $*$ & $*$ & $*$ & $*$ & $*$ \\
\hline 7. $\mathrm{pb}$ & $* !$ & $*$ & $*$ & $*$ & $*$ & $*$ & $*$ \\
\hline 8. $\mathrm{pd}$ & $* !$ & $*$ & $*$ & $*$ & $*$ & $*$ & $*$ \\
\hline 9. $\mathrm{pg}$ & $* !$ & $*$ & $*$ & $*$ & $*$ & $*$ & $*$ \\
\hline 10. pf & $*$ & $* !$ & $*$ & $*$ & $*$ & $*$ & $*$ \\
\hline 11. $\mathrm{p} \theta$ & $*$ & $* !$ & $*$ & $*$ & $*$ & $*$ & $*$ \\
\hline 12. ps & $*$ & $* !$ & $*$ & $*$ & $*$ & $*$ & $*$ \\
\hline 13. pš & * & $* !$ & $*$ & $*$ & $*$ & $*$ & $*$ \\
\hline 14. ph & $*$ & $* !$ & $*$ & $*$ & $*$ & $*$ & $*$ \\
\hline 15. pv & $*$ & $* !$ & $*$ & $*$ & $*$ & $*$ & $*$ \\
\hline 16. pð & $*$ & $* !$ & * & $*$ & $*$ & $*$ & $*$ \\
\hline 17. $\mathrm{pz}$ & * & $* !$ & $*$ & $*$ & $*$ & $*$ & $*$ \\
\hline 18. pž & $*$ & $* !$ & $*$ & $*$ & $*$ & $*$ & $*$ \\
\hline 19. pč & $*$ & $*$ & $* !$ & $*$ & $*$ & $*$ & $*$ \\
\hline 20. p ǰ & $*$ & $*$ & $* !$ & $*$ & $*$ & $*$ & $*$ \\
\hline 21. $\mathrm{pm}$ & $*$ & $*$ & $*$ & $*$ & $* !$ & $*$ & $*$ \\
\hline 22. pn & $*$ & $*$ & $*$ & * & $* !$ & $*$ & $*$ \\
\hline 23. py & $*$ & $*$ & $*$ & $*$ & $* !$ & $*$ & $*$ \\
\hline 24. pw & * & $*$ & $*$ & $*$ & $*$ & $* !$ & $*$ \\
\hline 24. $\mathrm{pM}$ & $*$ & $*$ & $*$ & $*$ & $*$ & $* !$ & $*$ \\
\hline
\end{tabular}

All the candidates of two-consonant onsets that are generated from a given input are ranked in the leftmost column in strictly ranked candidates, with reference to the number of constraints, while in the topmost row are double-output clusters. Those that incur fewer violations are ranked higher on the constraint hierarchy; the optimal candidates rank highest on the listed candidates. 
Table 3. Double Onset in the Corpus Data Table

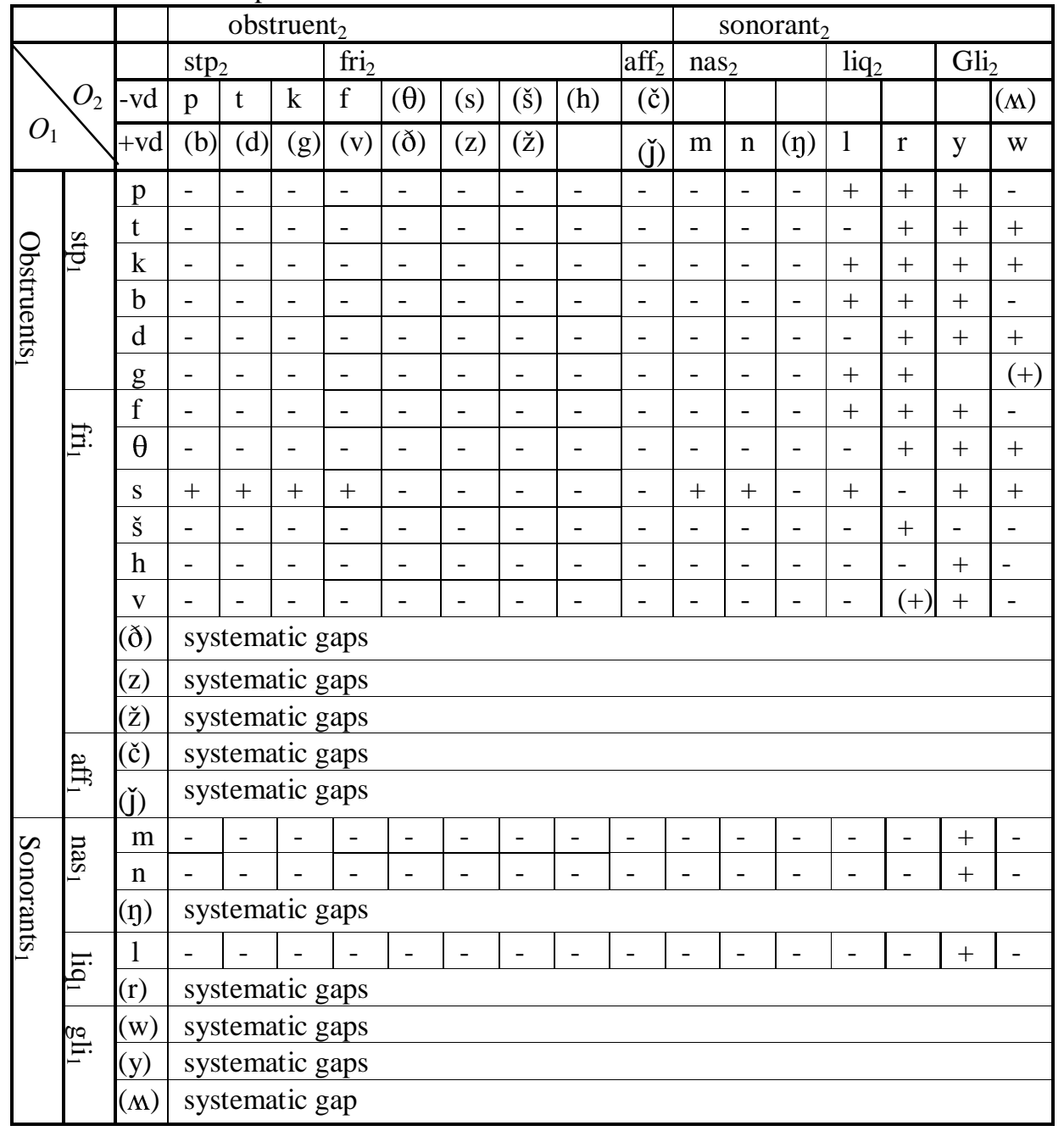

The double onsets in the table are those in the word initial $O_{1} O_{2}(V)$ tables tabulated by Gimson (1989). As all combinations in the corpus data table are well-formed candidates, there would be no erroneous analysis of the corpus data or no outputs that might violate or deviate from combinatory constraints. 
Table 4. Devoicing Assimilation in Digraph Onset Components

\begin{tabular}{|c|c|c|c|c|c|c|}
\hline \multirow[b]{2}{*}{ constraints } & \multicolumn{3}{|c|}{$\mathrm{s}_{1}+$ obstruent $_{2}$} & \multicolumn{3}{|c|}{$\mathrm{s}_{1}+$ sonorant $_{2}$} \\
\hline & $\mathrm{s}_{1}+\mathrm{stp}_{2}$ & $\mathrm{~s}_{1}+\mathrm{fri}_{2}$ & $\mathrm{~s}_{1}+\mathrm{aff}_{2}$ & $\mathrm{~s}_{1}+\mathrm{nas}_{2}$ & $\mathrm{~s}_{1}+\operatorname{liq}_{2}$ & $\mathrm{~s}_{1}+\mathrm{gli}_{2}$ \\
\hline sonority valu & $2+1$ & $2+2$ & $2+3$ & $2+4$ & $2+5$ & $2+6$ \\
\hline$\Rightarrow 1 . \mathrm{sl}$ & $*$ & $*$ & $*$ & $*$ & & $*$ \\
\hline$\Rightarrow 2 . \mathrm{sm}$ & $*$ & $*$ & $*$ & & $*$ & $*$ \\
\hline$\Rightarrow 3 . \mathrm{sn}$ & * & $*$ & $*$ & & $*$ & $*$ \\
\hline$\Rightarrow 4 . \mathrm{sw}(\mathrm{s} M)$ & $*$ & $*$ & $*$ & $*$ & $*$ & \\
\hline$\Rightarrow 5$. sy & $*$ & $*$ & $*$ & $*$ & $*$ & \\
\hline 6. $\mathrm{sf}$ & $*$ & $*$ & $*$ & $*$ & $*$ & $*$ \\
\hline 7. $\mathrm{sp}$ & $*$ & $*$ & $*$ & $*$ & $*$ & $*$ \\
\hline 8. st & $*$ & $*$ & $*$ & $*$ & $*$ & $*$ \\
\hline 9. sk & $*$ & $*$ & $*$ & $*$ & $*$ & $*$ \\
\hline 10. sb & $* !$ & $*$ & $*$ & $*$ & $*$ & $*$ \\
\hline 11. sd & $* !$ & $*$ & $*$ & $*$ & $*$ & $*$ \\
\hline 12. $\mathrm{sg}$ & $* !$ & $*$ & $*$ & $*$ & $*$ & $*$ \\
\hline 13. $s \theta$ & $*$ & $* !$ & $*$ & $*$ & $*$ & $*$ \\
\hline 14. ss & $*$ & $* !$ & $*$ & $*$ & $*$ & $*$ \\
\hline 15. šs & $*$ & $* !$ & $*$ & $*$ & $*$ & $*$ \\
\hline 16. sh & $*$ & $* !$ & $*$ & $*$ & $*$ & $*$ \\
\hline 17. sv & $*$ & $* !$ & $*$ & $*$ & $*$ & $*$ \\
\hline 18. sð & $*$ & $* !$ & $*$ & $*$ & $*$ & $*$ \\
\hline 19. sz & $*$ & $* !$ & $*$ & $*$ & $*$ & $*$ \\
\hline 20. sž & $*$ & $* !$ & $*$ & $*$ & $*$ & $*$ \\
\hline 21.sč & $*$ & $*$ & $* !$ & $*$ & $*$ & $*$ \\
\hline 22. š & $*$ & $*$ & $* !$ & $*$ & $*$ & $*$ \\
\hline 23. sr & $*$ & $*$ & $*$ & $* !$ & $*$ & $*$ \\
\hline 24. sy & $*$ & $*$ & $*$ & $*$ & $* !$ & $*$ \\
\hline
\end{tabular}

Twenty-four possible candidates are generated from an input by having $/ \mathrm{s}_{1} /$ combined with another segment as $/ \mathrm{O}_{2} /$ for the tableau in the standard optimality theory. Candidates 1-9 are permissible; they consist of $/ \mathrm{s}_{1} /$ and $/ \mathrm{O}_{2} /$, including the obstruents /p, t, k; f/ with SV's 1-2 and the sonorants /1; m, n, y, w/ with SV's 4-5. The voiceless feature of the initial voiceless segment influences its following sonorant to be devoiced or voiceless, whereas the voiceless obstruents remain unchanged in voice features. 